\title{
Exploring the Gender Digital Divide in E-Government Use in a Developing Country
}

Ali Acilar, University of Agder, Kristiansand, Norway

\begin{abstract}
This article explores the gender digital divide in e-government use in Turkey. Historical trends and differences in internet and e-government use by males and females are investigated. The findings of this study indicate that although internet use has increased over the years, there remains a steady and significant gap between males and females in terms of internet use and e-government services use. It appears that females in Turkey tend to be on the wrong side of the digital divide, and a significant number of females do not benefit from the potential advantages of the internet and e-government services. The gender digital gap in e-government use is higher than in internet use.
\end{abstract}

\section{KEYWORDS}

Developing Country, E-Government, Gender Digital Divide, Internet Use

\section{INTRODUCTION}

Technology, especially information and communication technology (ICT), has become an integral part of modern life. Today, people in their daily lives and most of the business have become almost dependent on these technologies. The ubiquity of the Internet is in our life grows incredibly with the pervasive use of smart mobile devices.

ICTs have affected almost all aspects of our lives, from education and health services to work and entertainment. These technologies, especially the Internet and WWW, have radically transformed the societies and the economies around the world over the last decades. Today, ICTs have become an essential part of modern societies and economies. As ICTs became more accessible and ubiquitous worldwide, a gap started to appear between users and non-users. This phenomenon is called a digital divide. Information and knowledge are recognized as power, and those without Internet access are increasingly being identified as the "information poor" (Morris, 2007). ICTs offer vast and new opportunities for human development and empowerment in areas ranging from education and the environment to healthcare and business; however, they are also the main contributing factors to social and economic inequalities across different social and economic groups (Moghaddam, 2010).

The Internet has become a vital resource in society (van Deursen \& van Dijk, 2014). In political, social, cultural, health, and economic domains, information and services are increasingly delivered online, and it is expected that they will be used by all (van Deursen \& van Dijk, 2014). Digital inclusion, enabling everyone to have access and capability to use the Internet and associated digital technologies, has wide-ranging benefits to the individual, the economy, and society (Olphert \& Damodaran, 2012). Being digitally disengaged has essential social, health, and economic disadvantages (Siren $\&$ Knudsen, 2017). ICTs have provided a new landscape of development for everyone, and women should get equal benefits provided by these technologies without exception (Bala \& Singhal, 2018). 
In the last century, there have been profound changes affecting our life dramatically all over the world. One of the most significant changes among them is the transformation of women's social role; women's participation in the workforce and daily life has been raised dramatically (GargalloCastel, Esteban-Salvador \& Pérez-Sanz, 2010). Even though there has been significant improvement in women's rights in the last century, women in many parts of the world still face serious social inequalities and issues, including violence, crime, illiteracy, discrimination, and mobbing. It is widely accepted that women, specifically living in developing countries, are discriminated against in many aspects of social life, including employment, income, political life, and education (Hilbert, 2011; Chang et al., 2012). The vast majority of women live in developing countries, and they suffer even more gender-related discrimination than their counterparts in developed countries (Hilbert, 2011). Even though much progress has been made in securing women's rights across the world in recent decades, some groups of women face additional forms of discrimination based on their age, ethnicity, nationality, religion, health status, marital status, education, disability, and socio-economic status, among other grounds (UN, 2014). Gender inequality is still one of the main problems, especially in developing countries (Chang et al., 2012). Gender discrimination and other gender problems are accepted as a global socio-economic problem, and therefore gender equity is listed on the United Nations' millennium development goals (3rd goal) and sustainable development goals (5th goal). ICT can help to tackle longstanding challenges of gender inequalities in developing countries, including access to employment, income, education, and health services (Hilbert, 2011).

Gender equality is not only a fundamental human right but also a necessary foundation for a peaceful, prosperous, and sustainable world (UN, OECD, 2018). Since the advantages that technology provides are being conveyed disproportionately to men in modern society, and women are disadvantaged in the process, we risk losing women's talents as contributors to science, technology, and the arts (Cooper, 2006). Economic and academic success have become dependent more and more on ICT; therefore, any inequality in interest or skill that differs systematically with gender is a problem for society (Cooper, 2006).

Despite a substantial increase in access and usage of ICTs worldwide, there are still significant challenges to overcome in ensuring women are included in the transformation to a digital-enabled society (Mariscal et al., 2019). Female users tend to use fewer digital services than men and are less confident in using the Internet (OECD, 2018). Existing researches show that women are less likely to access and use ICTs in developing countries (Primo, 2003; Hilbert, 2011; Alozie \& Akpan-Obong, 2017; Codoban, 2005). In developing countries, women tend to be on the wrong side of the digital divide. Males generally have more computer and Internet knowledge and experience than females and tend to use these technologies more (Codoban, 2005). Besides, women also present a lower frequency of ICTs use and less intensive Internet users than men (Bimber, 2000; Gargallo-Castel, Esteban-Salvador \& Pérez-Sanz, 2010). ICT access and use inequalities between genders can also be found in some of the developed countries.

The main aim of this study is to explore the gender digital divide in e-government use in Turkey, a developing country. Gender differences in Internet use and e-government use are explored. Even though there has historically been a significant gender digital divide in Turkey, only a relatively small body of research has been conducted on this important social issue. The gender digital divide in Turkey is not well focused and covered. It is particularly important to investigate the digital gender gap where gender discrimination is deeply embedded in society.

\section{LITERATURE REVIEW}

\section{The Gender Digital Divide}

The gender digital divide refers to unequal access and use of ICTs by females and males. Gender is important to understand ICT use in society, and therefore the gender divide is prominent in the 
digital divide literature. Studies on the digital divide reveal that gender is one of the essential factors in determining ICT adoption with economic status, race, and age. While men tend to be the first to use new technologies and to use them more, women are underrepresented both as users of computers and employees in the ICTs business (Gargallo-Castel, Esteban-Salvador \& Pérez-Sanz, 2010).

A considerable number of women in the many parts of the world continue to fall behind in opportunities to effectively use ICTs to improve their livelihoods, and if not properly addressed, the existing gender digital divide is likely to lead to gender inequalities in many other areas, including inequalities in labor markets and less financial inclusion of women (Mariscal et al., 2019). The consequences of the gender digital divide can be very severe for both women and society. Hilbert (2011) states that "traditionally, longstanding inequalities prevent women from accessing ICT, leading to a vicious circle between digital exclusion, unemployment, low income and lacking education." UNESCO recognizes the gender divide as "one of the most significant inequalities to be amplified by the digital revolution, and cuts across all social and income groups" (Primo, 2003).

Despite a substantial increase in access and usage of ICTs worldwide, there are still significant challenges to overcome in ensuring that women are included in the transformation to a digital-enabled society (Mariscal et al., 2019). As numerous areas of daily life and necessary services are delivered through digital technologies, digitally excluded women in the society are not able to benefit from the opportunities of engaging in the economy, from communicating and establishing social networks as well as from having access to improved public and private services (Mariscal et al., 2019).

"The digital divide is not simply an issue of access, but also of obstacles to Internet use. Even when women and men have equal access to the Internet either through home, work, or school, they may not have the opportunity to access the Internet or to engage in a wide variety of uses." (Kennedy, Wellman \& Klement, 2003). There are still gender differences in the nature, quality, and frequency of access to ICT (Gray, Gainous \& Wagner, 2017).

It is well documented that women in many parts of the world have fewer opportunities to access and use ICT (Abu-Shanab \& Al-Jamal, 2015). According to OECD 2018 report, the gender divide in Internet use is widening; while the global digital gender divide in Internet usage remained almost unchanged between 2013 and 2017, at about 11\%, the gap between developed and developing countries increased (OECD, 2018). Females generally fall on the wrong side of the digital divide, especially in the developing part of the world. Studies show that women in developing countries have significantly lower technology participation rates than men (Antonio \& Tuffley, 2014). A great number of women have difficulty accessing and using ICTs, especially in developing countries. Today, the most striking aspect of the digital divide in the world is the difference between women's and men's access to and use of ICT in developing countries (Singh, 2017).

It is difficult to see the magnitude of the gender divide worldwide. There are not many gender ICT statistics available for many countries (Hafkin \& Huyer, 2007). The absence of statistics is one of the main obstacles in measuring the digital divide in developing countries.

In addition to the lower technology adoption rate among women, some studies reveal that there are also gender differences in the purpose and intensity of ICT use. While ICTs are becoming ubiquitous in the developing countries, there are remaining differences in the platforms for access and quality of access as well as potential cultural and role differences in the way men and women utilize the Internet (Gray, Gainous \& Wagner, 2017). Jones et al. (2009) found that apparent gender differences emerged in relation to the activities college students pursued online. According to the results of their study, Jones et al. (2009) reported that "male college students spend greater amounts of time pursuing a wide variety of leisure activities online with greater frequency than females, including listening to and downloading music, watching and downloading videos." Miller \& Shrum (2011) found that women are less intense users of e-mail and the Web, and they use the Web less diversely than men. Hilbert (2011) found that men are much more enthusiastic about using the Internet for entertainment reasons than women, and women are less enthusiastic about applications of e-business and e-government. Jackson et al. (2008) found that males, regardless of race, were the most intense videogame players, 
and females, regardless of race, were the most intense cell phone users, instant messaged with friends and used e-mail more than did males from a sample of 515 children (average age 12 years old) in the USA. Jackson et al. (2008) also found that females were also more likely than males to use the Internet for academic purposes. Lim \& Meier (2011) found that significant differences existed between male and female Korean high school students in their use of computers in online activities. In their study, they found that males preferred game playing while females preferred social networking.

Some researchers argue that the gender digital divide tends to disappear in developed countries (Foteinou, 2010), with other differences between men and women are shrinking, including education and income (Bimber, 2000).

\section{Factors Contributing to the Gender Digital Divide}

There are a number of important factors behind the gender digital divide, including obstacles to access, (lack of) education and skills and technological literacy, affordability, and gender biases and socio-cultural norms, domestic responsibilities, geographic location, language, time, perceived benefits, self-confidence, computer anxiety (OECD, 2018; Primo, 2003; Huyer \& Mitter, 2003; Gill et al., 2010; Mumporeze \& Prieler, 2017; Bala \& Singhal, 2018)

Illiteracy is an important obstacle for women and girls to access online services (OECD, 2018). According to UNESCO 2018 data, $82.77 \%$ of women (15+years) worldwide are literate, compared to $89.84 \%$ of men (15+years). Women in developing countries generally do not receive the basic education and training needed to be ready technology adopters, and they are often seen only as "users" or "receivers" of technology (Gill et al., 2010). Digital literacy causes lack of comfort in using technology and accessing the Internet (OECD, 2018). Bala \& Singhal (2018) explored the extent of the gender digital divide in Uttar Pradesh in India and found that approximately 55 percent of women lack basic technological skills to use the Internet which makes them uncomfortable to use new Internet technologies.

Since the adoption of ICTs is a function of the potential adopters' income level, women's lower per capita income and lower literacy rate partly explain the existing gender bias in terms of the adoption of the Internet and other ICTs (Dholakia, Dholakia \& Kshetri, 2004). Higher-income developed countries have a small gender access divide comparing with the low-income developing countries (Gray, Gainous \& Wagner, 2017). Mariscal et al. (2019) state that poverty and socio-cultural norms that affect women's educational opportunities are primarily responsible for the digital gender divide. Less access to financial resources to cover the cost of equipment and access is one of the main barriers to women's access to and use of ICTs (Huyer \& Sikoska, 2003). In developing countries, several economic inequalities widen the gap of the digital divide, such as low personal income and savings, high cost of ICT infrastructure, a large number of dependents in a family, and inherited debt (Bala \& Singhal, 2018). Because of low female labor force participation, low wages, and unpaid work, women in developing countries have faced severe economic obstacles. Therefore, affordability affects disproportionally more females and remains one of the key hurdles in accessing ICTs (OECD, 2018). In addition, economic limitations and poverty affect women's educational opportunities and deepens the divide (Mariscal et al., 2019). In many parts of the world, the majority of the women population does not have economic freedom. According to the United Nations, women's economic empowerment is crucial to accomplishing gender equality and sustainable development. Hilbert (2011) analyzed data sets from 12 Latin American and 13 African countries from 2005 to 2008 and found that the reason why fewer women access and use ICT is a direct result of their unfavorable conditions with respect to employment, education, and income.

Living in an urban area can be a primary barrier for women to access ICT. Inadequate technological infrastructure in the area can hinder women's and girls' access to and usage of ICTs (Singh, 2017). In the developing countries, the majority of women live in remote and rural areas where there is a lack of telecommunications infrastructures, such as broadband and cell phone towers (Primo, 2003; OECD, 2018) and travel to ICT centres is more difficult due to cost, time, and cultural reasons in 
these areas (Huyer \& Sikoska, 2003). If Internet access is not available in the home, and women have to travel long distances to access the Internet, this is likely to reduce women's likelihood of pursuing the online environment (Antonio \& Tuffley, 2014).

Socio-cultural factors play an important role in explaining the digital gender divide (OECD, 2018) and are cited as main barriers to access ICT for many women (Mariscal et al., 2019). Sociocultural barriers are "factors that subtly or explicitly impel certain groups to censor their speech and behavior, or exclude themselves from particular activities, in the belief that these are not intended for them." (Primo, 2003). Culture is an essential determinant of behavior. According to Schein (1990, 18), culture is defined as "A pattern of shared basic assumptions learned by a group as it solved its problems of external adaptation and internal integration, which has worked well enough to be considered valid and, therefore, to be taught to new members as the correct way to perceive, think, and feel in relation to those problems."

Society has a critical position in shaping gender roles. Kennedy, Wellman \& Klement (2003) state that "Gender roles are socially constructed through institutions such as family, media, religion, education, and are pervasive in daily routines. Gender roles frame actions and shape behaviors." Gender role definition in society underlies many of the reasons why women do not make sufficient use of technology (Antonio \& Tuffley, 2014). Computer attitudes and behaviors can be affected by expectations from parents, school, and society for boys and girls (Lim \& Meier, 2011). The digital gender divide is not caused by gender or technology itself, but technology may reinforce or unveil gender inequalities rooting already in society (Bimber, 2000, Foteinou, 2010).

Gender and technology, including ICT, are not culturally neutral but have obtained particular meanings through social and cultural processes (Misu, 2001; Huyer \& Sikoska, 2003; Dholakia, Dholakia \& Kshetri, 2004). "The use of ICTs and other technologies by women and men reflects to a large extent the wider socio-cultural and economic context within which the technologies are produced and used" (Huyer \& Sikoska, 2003). Socio-cultural norms can drive gender stereotypes concerning the use of technologies, and these stereotypes are often reinforced in girls' closest environments, their families (Mariscal et al., 2019). Women in many parts of the developing countries are being denied or are denying themselves access to ICT, and they have significantly lower technology participation rates than men, because of some socio-cultural reasons, for example, accepting that women's place in society is only in the home (Antonio \& Tuffley, 2014). It was found that one-fifth of women living in India and Egypt believe that the Internet was not appropriate for them for some cultural reasons (OECD, 2018).

Culture can cause gender bias in technology adoption in several ways (Dholakia, Dholakia \& Kshetri, 2004): "First, cultural factors determine the level of involvement of men and women in technology related decisions. Second, culture is one of the important factors in determining the likelihood of learning the skills required for Internet use. Third, culture influences the adoption of a technology by making the alternative technologies more or less attractive in performing a function."

Due to socio-cultural influences, the features included in the design of a technology tend to favor men rather than women (Dholakia, Dholakia \& Kshetri, 2004). Therefore, the masculine image of computers may lead many females to avoid learning and using computers (He \& Freeman, 2010).

Safety-related issues can be the main reason for families' opposition to the use of the Internet or the ownership of a mobile phone for both women and girls in developing and emerging economies, in order to prevent from gender-based violence, including cyberstalking, online harassment, or even sexual trafficking (OECD, 2018). Bala \& Singhal (2018) reported that some women are not allowed to access Internet cafés, and telecenters as such places are considered unsafe by their family members.

Ono and Zavodny (2007) found that gender is a strong determinant of IT usage in a society with high degrees of gender inequality. For example, a sizeable gender gap in IT access and use persists in Japan, where gender inequality is higher than in most other industrialized nations (Ono \& Zavodny, 2007). 
New ICTs may not assure positive results on women's position in society. Garcia (2011) investigated the role of mobile phones among Latina farmworkers in Southeast Ohio and found that mobile phones are not essentially empowering to women, and under specific circumstances, they can serve as a device that strengthens hierarchical power relations between women and men. Gender status beliefs may be slow to follow social structural changes associated with the technological developments so that new inequalities might emerge to replace the old (Miller \& Shrum, 2011).

Domestic roles, such as raising children, making food, and taking care of the home, can prevent women from accessing and using new technologies. Especially in developing countries, women bear an excessively heavy burden of household and family responsibilities, and due to the combination of domestic duties and their role in society as primary caretakers, women do not have much time left to use new technologies (Antonio \& Tuffley, 2014). Technology participation by women in developing countries are significantly related with societal roles of women being primarily concerned with childrearing and housekeeping (Antonio \& Tuffley, 2014). Gendered expectations in terms of work and family roles may make it difficult for women to develop the skills needed for diverse use of technology even women can virtually access the technology (Miller \& Shrum, 2011).

Gender differences in the adoption of technology start very early in life (van Dijk, 2012), and have been associated with factors including computer access, scarce presence of computer games sensitive to gender differences, lack of role models, the way children learn to use computers and to interact with them, together with social expectations (Sainz, Castaño \& Artal, 2008). According to Cooper (2006), the roots of the gender digital divide "are embedded in social developmental differences between boys and girls, societal stereotypes of what is appropriate for the two genders and gender-specific attributional patterns."

Women often have complex relationships with technology as a result of being socialized to believe that technology and machines are a man's domain and not for women and girls, thus generating a gender bias in attitudes towards studying or using information technology (Primo, 2003). The common stereotype that men and boys are more interested in, and are more competent at, the use of computers, is an essential barrier for women and girls to use ICTs (Cooper, 2006). Believing this stereotype can cause negative feelings, avoidance, and poor performance among women (Cooper, 2006).

Computer anxiety and technophobia, which is fear of technology and distrust in its benefits, are substantial barriers to computer and Internet access, especially among people with low educational level, elders, and a part of the female population (van Dijk, 2008; Primo, 2003). Cooper (2006) suggests that "the digital divide is fundamentally a problem of computer anxiety whose roots are deep in socialization patterns of boys and girls and that interact with the stereotype of computers as toys for boys." Hilbert (2011) stated that females were seen as being more likely to be technophobic and were ascribed certain computer anxiety. He \& Freeman (2010) found that female college students feel less confident with computers and feel more anxious about using computers when compared with male counterparts. In numerous studies, girls and women report that computers are the source of anxiety across a broad spectrum of activities (Cooper, 2006).

Another reason for the gender digital divide is the lack of awareness of the potential benefits that the Internet may bring (OECD, 2018). If women's perceptions of using ICTs are low, they are not much likely to use these technologies, regardless of whether or not access is available (Antonio \& Tuffley, 2014).

\section{METHODOLOGY}

In this study, the gender digital divide is explored using the ICT Usage Surveys on Households and Individuals carried out by the Turkish Statistical Institute (TurkStat). The ICT Usage Surveys on Households and Individuals is conducted every year by TurkStat to obtain information related to ICT equipment and their usage by households and individuals in Turkey. It has been carried out since 2004 (except 2006), and it is the main data source on ICT usage by individuals in Turkey. 


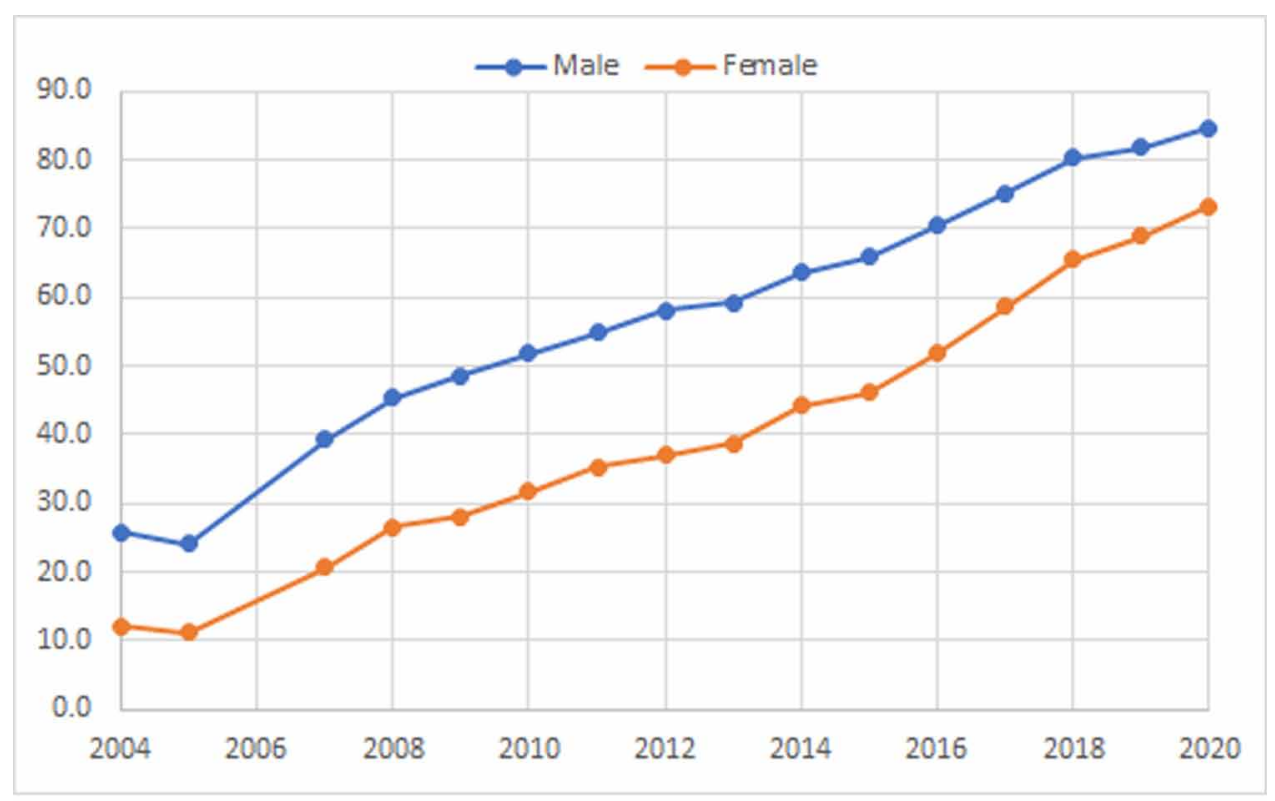

Source: TurkStat

Even though Turkey has significant ICT resources and infrastructure, there are various challenges that hinder its ability to benefit from ICTs, such as a high level of unemployment, unequal income distribution, a low level of education, inadequate community-based organizations, a high level of digital access division, a lack of policies towards universal access and a lack of connectivity at a reasonable cost for under-served areas, together with a variety of gender issues and barriers in ICTrelated fields (Törenli, 2006).

The rate of Internet use in Turkey has increased from 18.8 percent in 2004 to 79 percent in 2020. Internet use has increased among both males and females between 2004 and 2020. However, the rate of Internet use among women rose from 12.1 percent to 73.3 percent, while it rose from 25.7 percent to 84.7 percent among men. Despite this increase in the number of Internet users, there is still a significant gender gap in Internet use presents over the years. Comparing to Europe, user rates in Turkey are still much lower, and there is a more substantial gender gap in Internet use. In Europe, the Internet penetration rates for men and women are reported as 84.9 percent and 80.3 percent, respectively (ITU, 2019). TurkStat survey results reveal a dramatic gap between males and females in Internet use. The gap between men and women in terms of Internet use is very apparent and significant over the years. There is a slight decrease in the gender gap in the last five years, but it is still high enough. The trends of Internet use by gender are shown in Figure 1.

Table 1 shows the rates of individuals using the Internet in the last three months by age groups and gender. The Internet usage gap between males and females is consistently present for all age groups. Females in Turkey tend to lag behind males in terms of Internet use for all age groups. In 2019 , Internet use rates among males and females in 16-24 were $94.8 \%$ and $86.6 \%$, respectively. But for the $65-74$ age group, these rates were $25.3 \%$ and $15.0 \%$. The gender gap is smaller among younger people ( $<34$ age) than older people $(\geq 55$ age). It is a hopeful sign that the gender gap has begun to shrink among the younger generation over the last years. 
Table 2 presents the rates of individuals using the Internet in the last three months by education level and gender. Survey results indicate that there is a positive relationship between education level and Internet use. As the education level increases, Internet use rate also increases, and the gender gap decreases, as expected. Among higher educated people, the rate of Internet use for females is more elevated than for males over the last five years.

Table 3 presents Internet use rates for private purposes in the last three months by gender. It can be seen from Table 3 that Internet use among males and females for different activities is similar. For both males and females, "using instant messaging" is the most reported purpose of using the Internet, and "taking part in on-line consultations or voting to define civic or political issues" is the least reported purpose. In general, the rates of Internet use for males in the activities listed in Table 3 are higher than for females. Especially in activities, such as Internet banking and sending/receiving e-mails, Internet use rates for males are much higher than for females. Only the Internet use rates for communication purposes (Telephoning over the Internet and using instant messaging) and seeking health-related information are higher for females than males.

The use of e-government services among the Turkish population has increased over the years, but it is still not sufficient enough. Turkey ranked 53th in the United Nations E-Government Development Index in 2020. According to Turksat, 51.5\% of Internet users (16-74 years old) interacted with public authorities over the Internet in the last 12 months (April 2019-March 2020). This proportion is $62.1 \%$ for males and $41.1 \%$ for females. $53 \%$ of females (16-74 years old) in the European Union (27 countries) interacted with public authorities over the Internet, according to Eurostat 2019 data. Table 4 presents the rates of individuals (males, females, and total (males and females together)) using the Internet for interaction with public authorities.

According to TurkStat survey results, the rates of e-government use for listed purposes in Table 5, "obtaining information from public authorities' websites," "downloading official forms," and "submitting completed forms" are $48.7 \%, 24.5 \%$, and $28.6 \%$, respectively in 2020 . There is a significant

Table 1. Individuals using the Internet in the last three months by age groups and gender, (\%)

\begin{tabular}{|c|c|c|c|c|c|c|c|c|c|c|c|c|}
\hline \multirow[b]{3}{*}{ Year } & \multicolumn{12}{|c|}{ Age Groups } \\
\hline & \multicolumn{2}{|c|}{$16-24$} & \multicolumn{2}{|c|}{$25-34$} & \multicolumn{2}{|c|}{$35-44$} & \multicolumn{2}{|c|}{$45-54$} & \multicolumn{2}{|c|}{$55-64$} & \multicolumn{2}{|c|}{$65-74$} \\
\hline & Male & Female & Male & Female & Male & Female & Male & Female & Male & Female & Male & Female \\
\hline 2004 & 38.3 & 15.9 & 21.5 & 9.9 & 13.9 & 4.9 & 9.3 & 1.7 & 2.7 & 0.6 & 0.9 & 0.1 \\
\hline 2005 & 37.4 & 18.8 & 22.5 & 10.6 & 14.3 & 5.0 & 10.1 & 2.4 & 3.8 & 0.9 & 1.8 & 0.1 \\
\hline 2007 & 63.5 & 36.2 & 41.5 & 23.1 & 33.2 & 14.4 & 23.2 & 6.5 & 7.5 & 1.8 & 2.1 & 0.6 \\
\hline 2008 & 67.1 & 43.4 & 52.3 & 30.4 & 37.7 & 20.8 & 27.1 & 11.6 & 11.9 & 2.2 & 2.5 & 0.9 \\
\hline 2009 & 74.1 & 46.0 & 57.2 & 32.9 & 40.3 & 19.9 & 26.7 & 10.5 & 9.5 & 3.1 & 3.1 & 1.2 \\
\hline 2010 & 76.6 & 49.9 & 60.9 & 40.2 & 43.5 & 25.7 & 31.9 & 12.9 & 12.6 & 3.2 & 4.2 & 1.6 \\
\hline 2011 & 76.5 & 55.9 & 65.4 & 44.9 & 50.4 & 28.9 & 32.1 & 13.2 & 16.0 & 5.0 & 4.5 & 1.2 \\
\hline 2012 & 80.6 & 55.4 & 69.6 & 47.2 & 53.3 & 31.8 & 34.8 & 16.2 & 18.5 & 5.6 & 6.4 & 1.3 \\
\hline 2013 & 80.1 & 57.5 & 69.1 & 48.4 & 56.7 & 34.4 & 34.7 & 15.1 & 16.8 & 5.7 & 7.5 & 1.5 \\
\hline 2014 & 82.8 & 63.2 & 76.8 & 57.4 & 63.7 & 40.2 & 40.7 & 20.0 & 21.5 & 9.3 & 8.8 & 1.8 \\
\hline 2015 & 85.1 & 68.9 & 81.3 & 62.0 & 69.0 & 41.7 & 43.7 & 24.2 & 22.9 & 11.6 & 8.8 & 2.8 \\
\hline 2016 & 92.0 & 76.5 & 86.7 & 70.7 & 77.2 & 53.5 & 51.8 & 30.6 & 28.9 & 13.3 & 12.5 & 5.8 \\
\hline 2017 & 91.5 & 82.9 & 92.6 & 78.7 & 84.0 & 63.8 & 62.5 & 40.9 & 34.9 & 19.8 & 15.6 & 7.5 \\
\hline 2018 & 94.7 & 86.5 & 94.5 & 85.6 & 88.3 & 73.0 & 71.8 & 51.1 & 47.8 & 30.8 & 23.0 & 11.9 \\
\hline 2019 & 94.8 & 86.6 & 95.2 & 88.2 & 91.9 & 79.9 & 77.3 & 59.6 & 52.2 & 33.2 & 25.3 & 15.0 \\
\hline
\end{tabular}

Source: TurkStat 
Table 2. Individuals using the Internet in the last three months by education level and gender, (\%)

\begin{tabular}{|c|c|c|c|c|c|c|c|c|c|c|}
\hline & \multicolumn{2}{|c|}{$\begin{array}{c}\text { Literate without a } \\
\text { diploma }\end{array}$} & Primary school & \multicolumn{2}{c|}{$\begin{array}{c}\text { Secondary } \\
\text { and vocational } \\
\text { secondary school }\end{array}$} & \multicolumn{2}{c|}{$\begin{array}{c}\text { High and } \\
\text { vocational high } \\
\text { school }\end{array}$} & \multicolumn{2}{c|}{ Higher education } \\
\hline Year & Male & Female & Male & Female & Male & Female & Male & Female & Male & Female \\
\hline 2004 & 2.0 & 0.2 & 2.3 & 0.4 & 22.5 & 9.5 & 37.7 & 19.3 & 61.4 & 58.0 \\
\hline 2005 & 1.0 & 0.2 & 3.1 & 0.3 & 18.3 & 9.8 & 36.5 & 27.1 & 65.7 & 57.9 \\
\hline 2007 & 2.6 & 0.2 & 9.0 & 3.9 & 36.4 & 23.3 & 66.8 & 49.1 & 83.9 & 80.7 \\
\hline 2008 & 6.5 & 0.8 & 14.0 & 5.9 & 45.2 & 35.6 & 69.7 & 57.0 & 87.6 & 85.1 \\
\hline 2009 & 5.6 & 1.1 & 14.5 & 7.7 & 58.6 & 43.5 & 76.0 & 62.4 & 89.0 & 85.8 \\
\hline 2010 & 8.7 & 1.1 & 18.7 & 9.6 & 59.7 & 46.2 & 72.1 & 66.6 & 90.1 & 88.8 \\
\hline 2011 & 6.8 & 1.6 & 20.0 & 11.5 & 63.8 & 49.7 & 75.6 & 70.2 & 91.5 & 90.3 \\
\hline 2012 & 10.0 & 1.6 & 22.0 & 13.5 & 63.8 & 49.4 & 79.7 & 71.3 & 93.1 & 92.8 \\
\hline 2013 & 6.1 & 1.5 & 22.5 & 13.4 & 65.9 & 50.7 & 76.5 & 71.6 & 91.9 & 91.4 \\
\hline 2014 & 9.0 & 1.6 & 28.2 & 17.0 & 69.0 & 58.1 & 81.1 & 76.7 & 93.7 & 93.5 \\
\hline 2015 & 11.7 & 4.6 & 31.2 & 20.9 & 73.5 & 58.9 & 81.7 & 78.8 & 94.0 & 94.3 \\
\hline 2016 & 14.1 & 5.6 & 40.1 & 29.3 & 79.9 & 70.5 & 86.8 & 85.9 & 95.6 & 95.7 \\
\hline 2017 & 19.6 & 10.0 & 46.5 & 39.8 & 84.2 & 79.1 & 90.3 & 89.0 & 96.9 & 97.3 \\
\hline 2018 & 25.4 & 13.6 & 57.3 & 50.9 & 87.6 & 84.9 & 91.7 & 93.2 & 97.6 & 98.0 \\
\hline 2019 & 25.3 & 17.0 & 60.2 & 57.8 & 88.9 & 85.1 & 94.5 & 94.6 & 97.5 & 98.7 \\
\hline
\end{tabular}

Source: TurkStat

Table 3. Use of Internet for private purposes in the last three months by gender, 2019, (\%)

\begin{tabular}{|l|c|c|}
\hline \multicolumn{1}{|c|}{ Purposes } & Male & Female \\
\hline Sending/receiving e-mails & 52.5 & 38.8 \\
\hline Telephoning over the Internet / video calls (via webcam) over the Internet & 80.7 & 85.0 \\
\hline Participating in social networks (creating user profile, posting messages or other contributions) & 84.5 & 77.7 \\
\hline Using instant messaging & 93.3 & 94.6 \\
\hline Reading online news & 74.5 & 64.3 \\
\hline Seeking health-related information (e.g., injury, disease, nutrition, improving health, etc.) & 65.9 & 73.2 \\
\hline Finding information about goods or services & 68.5 & 60.9 \\
\hline Posting opinions on civic or political issues via websites & 25.8 & 20.9 \\
\hline Taking part in online consultations or voting to define civic or political issues & 11.0 & 6.8 \\
\hline Looking for a job or sending a job application & 11.2 & 9.9 \\
\hline $\begin{array}{l}\text { Uploading self-created content (text, photos, music, videos, software, etc.) to any website to be } \\
\text { shared }\end{array}$ & 44.5 & 40.2 \\
\hline Listening to music (e.g., web radio, music streaming) & 72.6 & 70.2 \\
\hline Selling of goods or services & 25.8 & 17.0 \\
\hline Internet banking & 59.0 & 33.0 \\
\hline
\end{tabular}

Source: TurkStat 
Table 4. Individuals using the Internet for interaction with public authorities, by gender in the last 12 months, (\%), 2007-2020

\begin{tabular}{|c|c|c|c|}
\hline Year & Total & Male & Female \\
\hline 2007 & 7.2 & 10.0 & 4.2 \\
\hline 2008 & 8.4 & 10.3 & 4.8 \\
\hline 2009 & 7.5 & 14.3 & 7.5 \\
\hline 2010 & 10.8 & 21.7 & 11.9 \\
\hline 2011 & 16.8 & 26.1 & 14.7 \\
\hline 2012 & 20.4 & 25.0 & 13.3 \\
\hline 2013 & 19.1 & 34.2 & 21.6 \\
\hline 2014 & 27.2 & 35.3 & 28.7 \\
\hline 2015 & 28.4 & 44.9 & 33.5 \\
\hline 2016 & 36.7 & 51.2 & 34.8 \\
\hline 2017 & 42.4 & 56.4 & 40.2 \\
\hline 2018 & 45.6 & 62.2 & 41.1 \\
\hline 2019 & 51.2 & 62.1 & 2 \\
\hline 2020 & 51.5 & & \\
\hline
\end{tabular}

Source: TurkStat

gap between males and females in interacting with public authorities and types of interaction over the Internet. In 2020, the rates of e-government services use for listed purposes for males are 59.4\%, $30.6 \%$, and $33.4 \%$, respectively. But for females, these rates are only $38.1 \%, 18.5 \%$, and $23.7 \%$. The survey results reveal that the gender digital gap in e-government use is higher than in Internet use. Table 5 shows the rates of individuals using the Internet for interaction with public authorities, by type of interaction and gender.

\section{DISCUSSION}

The TurkStat surveys reveal that there is a significant gender digital divide in both Internet and e-government use in Turkey. Despite the increase in Internet users, the gender digital divide in Internet use is consistently present for all age groups over the years in the Turkish population. There is also a significant difference between males and females in terms of interacting with public authorities and interaction types over the Internet. The rate of using the Internet for interaction with public authorities for females is less than for men. The existing male dominance in Turkish society plays an important role in the consistently present gender digital divide.

Turkey's total population is reported 83.2 million, with $49.8 \%$ female, by TurkStat in 2019 . In Turkey, women are struggling with inequalities and cultural barriers in society. Gender inequalities and male dominance in Turkish society can be observed in the institutions from family and education to the workplace and the parliament. According to TurkStat 2018 statistics, 7.6 percent of women were illiterate, whereas only 1.3 percent of men were illiterate; and the proportions of higher education graduates were 17.5 percent for females and 22.4 percent for males in the population aged 25 and over. Education is critically important to bridge the digital divide. Therefore, it is obvious that the necessary actions must be taken for gender equity in education in Turkey. Besides, TurkStat reported that the employment rate (in 15+ age) was $29.4 \%$ for females and $65.7 \%$ for males in 2018 , and women earned lower wages than men at all educational levels. 
Table 5. Individuals using the Internet for interaction with public authorities, by type of interaction and gender in the last 12 months, (\%), 2007-2020

\begin{tabular}{|c|c|c|c|c|c|c|c|c|c|}
\hline \multirow[b]{2}{*}{ Year } & \multicolumn{3}{|c|}{$\begin{array}{l}\text { Obtaining information from } \\
\text { public authorities' websites }\end{array}$} & \multicolumn{3}{|c|}{ Downloading official forms } & \multicolumn{3}{|c|}{ Submitting completed forms } \\
\hline & Total & Male & Female & Total & Male & Female & Total & Male & Female \\
\hline 2007 & 6.3 & 8.8 & 3.7 & 2.1 & 3.0 & 1.2 & 2.2 & 3.0 & 1.4 \\
\hline 2008 & 7.5 & 10.3 & 4.7 & 2.7 & 3.7 & 1.8 & 2.6 & 3.4 & 1.7 \\
\hline 2009 & 6.8 & 9.2 & 4.5 & 2.2 & 3.2 & 1.3 & 2.6 & 3.7 & 1.5 \\
\hline 2010 & 8.6 & 11.4 & 6.0 & 3.4 & 4.4 & 2.3 & 3.0 & 4.0 & 2.1 \\
\hline 2011 & 15.4 & 20.2 & 10.8 & 4.5 & 5.9 & 3.1 & 5.5 & 6.9 & 4.2 \\
\hline 2012 & 19.4 & 24.8 & 14.0 & 7.1 & 9.1 & 5.1 & 7.8 & 10.0 & 5.7 \\
\hline 2013 & 17.3 & 22.9 & 11.8 & 6.2 & 8.0 & 4.4 & 7.2 & 9.0 & 5.4 \\
\hline 2014 & 26.1 & 32.9 & 19.4 & 12.0 & 14.9 & 9.1 & 10.6 & 13.1 & 8.1 \\
\hline 2015 & 27.0 & 33.7 & 20.4 & 12.8 & 16.2 & 9.4 & 12.1 & 14.9 & 9.3 \\
\hline 2016 & 32.6 & 40.8 & 24.5 & 16.3 & 20.5 & 12.1 & 22.6 & 26.4 & 18.8 \\
\hline 2017 & 37.6 & 46.6 & 28.6 & 22.5 & 28.6 & 16.3 & 30.4 & 36.2 & 24.8 \\
\hline 2018 & 41.7 & 52.5 & 31.0 & 25.5 & 32.1 & 18.9 & 30.1 & 35.6 & 24.7 \\
\hline 2019 & 45.8 & 57.2 & 34.5 & 29.2 & 37.5 & 20.9 & 35.5 & 41.6 & 29.5 \\
\hline 2020 & 48.7 & 59.4 & 38.1 & 24.5 & 30.6 & 18.5 & 28.6 & 33.4 & 23.7 \\
\hline
\end{tabular}

Source: TurkStat

Historically, females are significantly underrepresented in the parliament and government in Turkey. Turkey is ranked 117th out of 192 countries in terms of the ratio of women deputies in the parliament. After the last election in 2018, the female representation rate only became $17 \%$. Only $3 \%$ of mayors are female. Turkey is ranked 130th out of 150 on the Global Gender Gap Report 2020 (The World Economic Forum, 2020) and 59th in the UN Gender Inequality Index in 2018.

The digital divide has the potential to widen existing inequalities in society. Therefore, if it is not appropriately addressed, the digital gender divide can widen the gender divide in education, employment, politics, etc., in Turkish society.

\section{CONCLUSION}

The purpose of the current study was to explore the gender digital divide in e-government use in Turkey. This study has shown that there is a significant gender digital divide in Turkey, and females are underrepresented in the total Internet audience. Findings suggest that although Internet use has increased over the years for both males and females, there remains a steady and significant gap between males and females in Internet use and e-government services use. It appears that females in Turkey tend to be on the wrong side of the digital divide, and a significant number of females do not benefit from the potential advantages of the Internet and e-government services. Besides, the survey result indicates that the digital gap between males and females will not disappear in the near future. The pace of change has been slow under long term male-dominated cultures.

The study has found that there is a significant gender gap in Internet use presents. Females tend to lag behind males in terms of Internet use for all age groups, but the gender digital gap is smaller among younger than older people in the last years. The survey results show that Internet use increases with education. As the education level increases, Internet use rate also increases, and the gender digital 
gap decreases. The use of e-government services among the Turkish population has increased over the years, but it is still not sufficient enough. There is a significant difference between males and females in terms of interacting with public authorities and interaction types over the Internet. The survey results reveal that the gender digital gap in e-government use is higher than in Internet use.

Gender itself is not a reason behind the digital divide. Socio-cultural and economic factors play an essential role in the access and use of ICT among females, especially in developing countries. Therefore, education is critically important to ensure gender equity and reduce the gender digital divide, as well as to ensure women's empowerment. From kindergarten to higher education, gender equity should be addressed in the curriculum and other activities, for example, in sport and cultural practices. It is crucial that gender equity should not be only on the policy papers; it must be put into action. 


\section{REFERENCES}

Abu-Shanab, E., \& Al-Jamal, N. (2015). Exploring the gender digital divide in Jordan. Gender, Technology and Development, 19(1), 91-113. doi:10.1177/0971852414563201

Alozie, N. O., \& Akpan-Obong, P. (2017). The digital gender divide: Confronting obstacles to women's development in Africa. Development Policy Review, 35(2), 137-160. doi:10.1111/dpr.12204

Antonio, A., \& Tuffley, D. (2014). The gender digital divide in developing countries. Future Internet, 6(4), 673-687. doi:10.3390/fi6040673

Bala, S., \& Singhal, P. (2018). Gender digital divide in India: A case of inter-regional analysis of Uttar Pradesh. Journal of Information. Communication and Ethics in Society, 16(2), 173-192. doi:10.1108/JICES-07-2017-0046

Bimber, B. (2000). Measuring the gender gap on the Internet. Social Science Quarterly, 81(3), 868-876.

Chang, Y., Shahzeidi, M., Kim, H., \& Park, M. C. (2012). Gender digital divide and online participation: A cross-national analysis. 19th ITS Biennial Conference 2012, Bangkok, Thailand.

Codoban, I. (2005). Internet usage and gender digital divide in a Romanian students' sample. PsychNology Journal, 3(3), 265-291.

Cooper, J. (2006). The digital divide: The special case of gender. Journal of Computer Assisted Learning, 22(5), 320-334. doi:10.1111/j.1365-2729.2006.00185.x

Dholakia, R. R., Dholakia, N., \& Kshetri, N. (2004). Gender and Internet usage. In H. Bidgoli (Ed.), The Internet Encyclopedia (pp. 12-22). Wiley. doi:10.1002/047148296X.tie070

Foteinou, G. (2010). E-exclusion and the gender digital divide. ACM SIGCAS Computers and Society, 40(3), 50-61. doi:10.1145/1862406.1862410

Garcia, O. P. M. (2011). Gender digital divide: The role of mobile phones among Latina farm workers in Southeast Ohio. Gender, Technology and Development, 15(1), 53-74. doi:10.1177/097185241101500103

Gargallo-Castel, A., Esteban-Salvador, L., \& Pérez-Sanz, J. (2010). Impact of gender in adopting and using ICTs in Spain. Journal of Technology Management \& Innovation, 5(3), 120-128. doi:10.4067/S0718-27242010000300009

Gill, K., Brooks, K., McDougall, I., Patel, P., \& Kes, A. (2010). Bridging the gender divide: How technology can advance women economically. International Centre for Research on Women. https://www.icrw.org/publications/ bridging-the-gender-divide/

Gray, T. J., Gainous, J., \& Wagner, K. M. (2017). Gender and the digital divide in Latin America. Social Science Quarterly, 98(1), 326-340. doi:10.1111/ssqu.12270

Hafkin, N. J., \& Huyer, S. (2007). Women and gender in ICT statistics and indicators for development. Information Technologies and International Development, 4(2), 25-41. doi:10.1162/itid.2008.00006

He, J., \& Freeman, L. A. (2010). Are men more technology-oriented than women? The role of gender on the development of general computer self-efficacy of college students. Journal of Information Systems Education, 21(2), 203-212.

Hilbert, M. (2011). Digital gender divide or technologically empowered women in developing countries? A typical case of lies, damned lies, and statistics. Women's Studies International Forum, 34(6), 479-489. doi:10.1016/j. wsif.2011.07.001

Huyer, S., \& Sikoska, T. (2003). Overcoming the gender digital divide: understanding ICTs and their potential for the empowerment of women. http://www.unesco.org/new/fileadmin/MULTIMEDIA/HQ/SHS/pdf/OvercomingGender-Digital-Divide.pdf

Huyer, S., \& Mitter, S. (2003). ICTs, globalisation and poverty reduction: Gender dimensions of the knowledge society. http://gab.wisat.org/PartI.pdf

ITU. (2019), Measuring digital development facts and figures 2019 https://www.itu.int/en/ITU-D/Statistics/ Documents/facts/FactsFigures2019.pdf 
Jackson, L. A., Zhao, Y., Kolenic, A. III, Fitzgerald, H. E., Harold, R., \& Von Eye, A. (2008). Race, gender, and information technology use: The new digital divide. Cyberpsychology \& Behavior, 11(4), 437-442. doi:10.1089/ cpb.2007.0157 PMID:18721092

Jones, S., Johnson-Yale, C., Millermaier, S., \& Pérez, F. S. (2009). US college students’ Internet use: Race, gender and digital divides. Journal of Computer-Mediated Communication, 14(2), 244-264. doi:10.1111/j.10836101.2009.01439.x

Kennedy, T., Wellman, B., \& Klement, K. (2003). Gendering the digital divide. ITandSociety, 1(5), $72-96$.

Lim, K., \& Meier, E. B. (2011). Different but similar: Computer use patterns between young Korean males and females. Educational Technology Research and Development, 59(4), 575-592. doi:10.1007/s11423-011-9206-5

Mariscal, J., Mayne, G., Aneja, U., \& Sorgner, A. (2019). Bridging the gender digital gap. Economics: The Open-Access. Open-Assessment E-Journal, 13(9), 1-12.

Miller, B. P., \& Shrum, W. (2011). The gender digital divide in the research sectors of Ghana, Kenya, and Kerala: Are women more connected over time? Gender, Technology and Development, 15(1), 25-52. doi:10.1177/097185241101500102

Misu, N. A. (2001). The cultural construction of the computer as a masculine technology: An analysis of computer advertisements in Korea. Asian Journal of Women's Studies, 7(3), 93-114. doi:10.1080/12259276.2001.11665911

Moghaddam, G. G. (2010). Information technology and gender gap: Toward a global view. The Electronic Library, 28(5), 722-733. doi:10.1108/02640471011081997

Morris, A. (2007). E-literacy and the grey digital divide: A review with recommendations. Journal of Information Literacy, 1(3), 13-28. doi:10.11645/1.3.14

Mumporeze, N., \& Prieler, M. (2017). Gender digital divide in Rwanda: A qualitative analysis of socioeconomic factors. Telematics and Informatics, 34(7), 1285-1293. doi:10.1016/j.tele.2017.05.014

Olphert, W., \& Damodaran, L. (2013). Older people and digital disengagement: A fourth digital divide? Gerontology, 59(6), 564-570. doi:10.1159/000353630 PMID:23969758

Organisation for Economic Co-operation and Development (OECD). (2018). Bridging the digital gender divide: include, upskill, innovate. http://www.oecd.org/internet/bridging-the-digital-gender-divide.pdf

Ono, H., \& Zavodny, M. (2007). Digital inequality: A five country comparison using microdata. Social Science Research, 36(3), 1135-1155. doi:10.1016/j.ssresearch.2006.09.001

Primo, N. (2003). Gender Issues in the Information Society. Paper prepared for the World Summit on the Information Society, Paris, France. https://unesdoc.unesco.org/ark:/48223/pf0000132967

Sainz, M., Castaño, C. Y., \& Artal, M. (2008). Review of the concept digital literacy and its implications in the study of the gender digital divide. UOC. https://www.uoc.edu/in3/dt/eng/sainz_castano_artal.pdf

Singh, S. (2017). Bridging the gender digital divide in developing countries. Journal of Children and Media, 11(2), 245-247. doi:10.1080/17482798.2017.1305604

The World Economic Forum. (2020). Global Gender Gap Report 2020. http://www3.weforum.org/docs/ WEF_GGGR_2020.pdf https://www.weforum.org/reports/gender-gap-2020-report-100-years-pay-equality

Turkish Statistical Institute (TurkStat). https://www.tuik.gov.tr/

Törenli, N. (2006). The 'other' faces of digital exclusion: ICT gender divides in the broader community. European Journal of Communication, 21(4), 435-455. doi:10.1177/0267323106070010

van Dijk, J. A. (2008). The digital divide in Europe. In The handbook of Internet politics. Routledge.

van Dijk, J. A. (2012). The evolution of the digital divide: The digital divide turns to inequality of skills and usage. Digital Enlightenment Yearbook, 57-75.

van Deursen, A. J., \& van Dijk, J. A. (2014). The digital divide shifts to differences in usage. New Media \& Society, 16(3), 507-526. doi:10.1177/1461444813487959 
World Bank Group. (2016). World development report 2016: digital dividends. World Bank Publications. https:// www.worldbank.org/en/publication/wdr2016

Ali Acılar is an associate professor of Management Information Systems. He graduated from the Department of Business Administration at Hacettepe University, Ankara, Turkey, received his MS in Operation Research and Statistics from Rensselaer Polytechnic Institute (RPI), Troy, NY, USA and obtained his Ph.D in Business Administration from Dumlupınar University, Kütahya, Turkey in 2007. His research interest includes information and communication technologies (ICTs) use by organizations and individuals, issues in ICT use, social media, e-commerce, and e-government. 